\title{
Pattern of glomerular diseases in biopsy proven native kidney in Western Nepal
}

\author{
Abhishek Maskey ${ }^{1}$, Lekhnath Lamsal ${ }^{2}$
}

${ }^{1}$ Associate professor, Department of medicine, Manipal teaching hospital, Pokhara, Nepal

${ }^{2}$ Resident, Department of medicine, Manipal teaching hospital, Pokhara, Nepal

Keywords: IgA Nephropathy, kidney biopsy, subnephrotic proteinuria

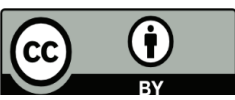

This work is licensed under a Creative Commons Attribution 4.0 Unported License.

\section{Abstract}

Background and Aims: Kidney biopsy is decisive while evaluating for the diagnosis of glomerular, vascular, tubulointerstitial and genetic diseases. There is paucity of data on prevalence and pattern of various types of kidney diseases in Nepalese population. We describe various types of kidney diseases in patient population undergoing kidney biopsy at our centre.

Methods: This is a prospective analysis of all patients, who underwent percutaneous renal biopsy at Manipal teaching hospital, over a duration of 30 months, i.e. August 2017 to January 2019. All kinds of kidney disease patients were included for kidney biopsy, irrespective of their clinical syndromes and underlying diagnosis.

Results: A total of 175 consecutive biopsies were analyzed. The mean age of the patient was $35 \pm 15$ years. Majority of the biopsy performed were in females. The majority of biopsy cases were age between 21-30 years of age. The youngest case to undergo renal biopsy was a child with asymptomatic isolated hematuria. The most frequent histological pattern observed in our study was IgA nephropathy (34.6\%), followed by Focal segmental glomerulosclerosis (15.45\%) and Membranous nephropathy (14.85\%). Regarding complication macroscopic hematuria was seen in $15(8.5 \%)$ cases and 8 $(4.5 \%)$ cases had perinephric hematoma. There was no death related to renal biopsy.

Conclusion: IgA nephropathy was the commonest histological pattern. Subnephrotic proteinuria was the commonest indication for biopsy. Complication of kidney biopsy is rare and considered safe procedure in clinical practice to determine diagnosis, prognosis and treatment.

Corresponding Author

Dr. Abhishek Maskey, Assoc. Professor

Department of medicine, Manipal teaching hospital,

Pokhara, Nepal. Email: maskey21@hotmail.com 
kidney diseases changes with the time. ${ }^{5}$ This study is conducted to identify the patterns of the glomerular diseases in native kidneys in patients in western Nepal.

\section{Materials and methods:}

A prospective, descriptive study of kidney biopsy was conducted. All kinds of kidney disease patients, irrespective of clinical syndromes, who underwent kidney biopsy were included in the study. Data was collected over a period of two and half years, from August 2017 to January 2019 in the Nephrology Unit, Manipal teaching hospital, Nepal.

The indications of renal biopsy was as per the standard indications. Patients with clinical features suggestive of diabetic nephropathy were excluded unless they had atypical features.

Using the self-adjustable, automated, spring loaded gun biopsy needle of 18 Gauge size, kidney biopsy was performed under ultrasonographic guidance. Two cores of renal tissue were taken during the biopsy procedure, one for light microscopy which was kept in $10 \%$ formalin and another core for Immunofluorescence in normal saline. Third core of renal tissue was obtained in very selected cases for electron microscopy. All the samples were sent to Dr. Lal's Path labs New Delhi, India to be reported by renal histopathologists.

Patients were monitored in the nephrology ward for 24 hours after the biopsy for observation of any complications. variable including various clinical renal syndromes, histological patterns, complications and outcomes associated with kidney biopsies were entered in preset proforma. A written consent was taken from each patient prior to the biopsy procedure, after explaining the risk and benefit of the procedure and the possible complications of the procedure.

After 24 hours of biopsy, USG-Kidney ureter and bladder (KUB) and urine routine microscopy were repeated for perinephric collection or hematoma and microscopic hematuria respectively. If there were no complication, then the patient was discharged after $24 \mathrm{hrs}$ of the procedure.

\section{Results}

\begin{tabular}{|r|r|r|r|}
\hline \multicolumn{4}{|c|}{ Table 1. Age and sex distribution of patients } \\
\hline Age ( years) & $\begin{array}{c}\text { Number } \\
\text { Count (\%) }\end{array}$ & \multicolumn{1}{|c|}{ Male } & \multicolumn{1}{|l|}{ Female } \\
\hline $11-20$ & $34(19.44)$ & 19 & 15 \\
\hline $21-30$ & $48(27.43)$ & 24 & 24 \\
\hline $31-40$ & $35(20)$ & 14 & 21 \\
\hline $41-50$ & $31(17.71)$ & 14 & 17 \\
\hline $51-60$ & $14(8)$ & 7 & 7 \\
\hline $61-70$ & $7(4)$ & 2 & 5 \\
\hline $71-80$ & $6(3.42)$ & 4 & 2 \\
\hline Total & 175 & 84 & 91 \\
\hline
\end{tabular}

Table 2. Frequency of various pathological lesions

\begin{tabular}{|l|c|c|}
\hline Histopathological pattern & Count & Percentage \\
\hline
\end{tabular}

\begin{tabular}{|l|r|r|}
\hline IgA Nephropathy & 64 & 36.60 \\
\hline Focal segmental glomerulosclerosis & 27 & 15.45 \\
\hline Membranous nephropathy & 26 & 14.85 \\
\hline Minimal change disease & 14 & 8.0 \\
\hline Lupus nephritis & 13 & 7.42 \\
\hline $\begin{array}{l}\text { Diffuse proliferative } \\
\text { glomerulonephritis }\end{array}$ & 9 & 5.14 \\
\hline Membranoproliferative & 4 & 2.28 \\
glomerulonephritis & 3 & 1.71 \\
\hline Acute interstitial nephritis & 3 & 1.71 \\
\hline Hypertensive nephropathy & 3 & 1.71 \\
\hline Pauci immune glomerulonephritis & 2 & 1.14 \\
\hline Myeloma kidney & 2 & 1.14 \\
\hline Diabetic Nephropathy & 1 & 0.57 \\
\hline Chronic glomerulonephritis & 1 & 0.57 \\
\hline Idiopathic nodular glomerulosclerosis & 1 & 0.57 \\
\hline Alport syndrome & 1 & 0.57 \\
\hline Thin basement membrane disease & 1 & 0.57 \\
\hline Amyloidosis & & \\
\hline
\end{tabular}

Table 3. Indication for kidney biopsy

\begin{tabular}{|l|r|r|}
\hline Indication for biopsy & Number & Percentage \\
\hline Subnephrotic proteinuria & 75 & 42.85 \\
\hline Nephrotic syndrome & 69 & 39.42 \\
\hline Isolated hematuria & 1 & 0.57 \\
\hline Rapidly progressive renal failure & 8 & 4.57 \\
\hline Lupus nephritis & 13 & 7.45 \\
\hline Acute nephritic syndrome & 9 & 5.14 \\
\hline
\end{tabular}

\begin{tabular}{|l|r|r|}
\hline \multicolumn{3}{|c|}{ Table 4. Complications and outcome } \\
\hline Complications & Number & Percentage \\
\hline Macroscopic hematuria & 15 & 8.5 \\
\hline Perinephric hematoma & 8 & 4.5 \\
\hline $\begin{array}{l}\text { Blood transfusion for biopsy } \\
\text { related bleeding }\end{array}$ & 1 & 0.6 \\
\hline Death & 0 & 0 \\
\hline Lupus nephritis & 13 & 7.45 \\
\hline Acute nephritic syndrome & 9 & 5.14 \\
\hline
\end{tabular}

A total of 175 consecutive biopsies were analyzed over a period of one and half years. The mean age of the patient was $35 \pm 15$ years. The age range of the patient undergoing renal biopsy was 11 years to 80 years. Majority of the biopsy performed were in females.

The majority of biopsy cases were age between 21-30 years of age. The youngest case to undergo renal biopsy was a child with asymptomatic isolated hematuria. 
The most frequent histological pattern observed in our study was IgA nephropathy (64), followed by FSGS and MGN and so forth which is depicted in table

In our study 15 cases had macroscopic hematuria, 8 patients had perinephric hematoma. One case needed blood transfusion related with biopsy complication. There was no death related to renal biopsy. Subnephrotic proteinuria was the most common indication for renal biopsy.

\section{Discussion}

Pattern of glomerular disease varies worldwide. Studies from various parts of Nepal showed different incidence and prevalence of glomerulonephritis. There is paucity of data on biopsy proven native kidney disease in western Nepal.

In our study, we observed that two-third of patient undergoing biopsy were age less than 40 years. This is similar to studies done in Nepal by Ghimere et al and Manandhar et al. ${ }^{3,4}$ Likewise studies conducted in our neighboring countries like India and Pakistan had mean age of 38 years and 32.27 years respectively. 6,7 This indicates disease burden in younger age group.

Our study showed that kidney disease were slightly higher in the female population compared to males. Similar findings were seen in studies conducted by Mukunda et al and Abhushan et al in Nepal. ${ }^{8,9}$ However, study done in Italy by Roccatello $D$ et al and in India by Singh P et al and in Nepal by Sharma A et al showed male predominance in their study. ${ }^{10,11,12}$

Various studies done in Nepal by khakurel $\mathrm{S}$ et al, Aryal G et al, Kafle et al, Manandhar et al showed MPGN (21\%), MGN (42.3 $\%)$, Lupus nephrtis $(21 \%)$, MCD $(26 \%)$ respectively as their most common hisptopathological pattern. ${ }^{4,8,13,14}$ However, our study showed IgA Nephropathy (36.6\%) as the most common pattern. This shows there is heterogenicity in histopathological pattern of biopsy proven kidney disease signifying variation of kidney disease in central and western Nepal.

IgAN is the most common form of GN worldwide comprising $45 \%$ of all primary GN cases..$^{15}$ There is high prevalence of IgAN in Asian countries. ${ }^{16}$ The frequency with which it is diagnosed varies between and within countries, mostly according to local protocol regarding the indications of kidney biopsy. ${ }^{17}$ Our findings are consistent with other European (22\%) and around 32 to $42 \%$ in East/ Southeast Asia where prevalence of $\lg A \mathrm{~N}$ is higher than Europe. ${ }^{18,19,20}$

Our study showed FSGS (27\%) to be the second common histological pattern. Likewise, studies done by Khakurel et al and Sharma et al also showed FSGS as second common disease. ${ }^{12,13}$ In African country, where there is predominance of black race, FSGS accounted for $67 \%$ of primary glomerulonephritis. ${ }^{21}$ Various studies have shown that FSGS as the commonest cause of primary nephrotic syndrome in the US. ${ }^{22}$

Barden et al reported an increasing incidence of FSGS when compared to membranous nephropathy. ${ }^{23}$ Membranous nephropathy is the leading cause of NS in adults. MN accounts for $26 \%$ of all cases in our study. Studies done by Mukunda et al and Manandhar et al showed $8.2 \%$ and $18.2 \%$ respectively.
Idiopathic nodular glomerulosclerosis is an enigmatic condition that resembles nodular diabetic glomerulosclerosis but occurs in nondiabetic patients. Only one case $(0.57 \%)$ was found to have idiopathic nodular glomerulosclerosis. Our patients had history of hypertension and smoking however no history of diabetes mellitus. Similar results was observed in study done by Marokowitcz et al. ${ }^{24}$

The most common indication for renal biopsy was subnephrotic proteinuria which consists of $42.85 \%$ of total biopsied patients. Similar findings were observed in study done by Ghimere et al. however, nephrotic syndrome was the commonest indication of biopsy in study done by Imtiaz et al and Mukunda et al. ${ }^{4,7}$

Kidney biopsy is safe procedure and the risk of development of major complications is very rare.1 Biopsy related complication in our study were few and comparable with other studies. Macroscopic hematuria and perinephric hematuria was seen in $8.5 \%$ and $4.5 \%$ respectively. Medelssoohn and Cole found an overall complications rate of $5.3 \%$ in their study. One patient with lupus nephritis needed blood transfusion after biopsy. Various predictors for bleeding in lupus nephritis has been studied. Among them, prebiopsy platelet count strongly predicts the risk of bleeding. ${ }^{25}$

This study is not without limitation. Our biopsy sample were not examined with electron microscopy in majority of the patient.

In conclusion, IgA nephropathy was the commonest histological pattern in our study. Subnephrotic proteinuria was the commonest indication for biopsy. Complication of kidney biopsy is rare and considered safe procedure in clinical practice to determine diagnosis, prognosis and treatment.

\section{References}

1. Visconti L, Cernaro V, Ricciardi CA, Lacava V, Pellicanò V. Renal biopsy: Still a landmark for the nephrologist. World J Nephrol 2016; 5(4): 321-27

2. Whittier $\mathrm{WL}$, Korbet SM. Timing of complications in percutaneous renal biopsy. J Am Soc Nephrol. 2004;15:142-7.

3. Ghimire M, Pahari B, Paudel N, Das G,1 Das GC, Sharma SK. Kidney Biopsy: An Experience from Tertiary Hospital.J Nepal Med Assoc 2014;52(193):707-12

4. Manandhar DN, Chhetri PK, Poudel P, Singh N, Baidya SK. Spectum of glomerular diseases in native kidneys in patients attending Nepal Medical College Teaching Hospital. Journal of Advances in Internal Medicine 2016;05(02):24-28.

5. Chang JH, Kim DK, Kim HW et al. Changing prevalence of glomerular diseases in Korean adults: a review of 20 years of experience. Nephrol Dial Transplant 2009;24:2406-10 doi:10.1093/ndt/gfp091

6. Das U, Dakshinamurty KV, Prayaga A. Pattern of biopsyproven renal disease in a single center of south India: 19 years experience. Indian J Nephrol. 2011;21(4):250-7. doi: 10.4103/0971-4065.85482.

7. Imtiaz S, Murtaza F. D., Nasir K, Salman B, Ahmad A. Analysis of Renal Diseases Detected in Renal Biopsies of Adult Patients: A Single-Center Experience. Saudi J Kidney Dis Transpl 2017;28(2):368-378 
8. Kafle MP, Shah DS, Shrestha S, Sigdel MR, Raut KB. Prevalence of specific types of kidney disease in patients undergoing kidney bopsy: a single centre experience. Journal of Advances in Internal Medicine 2014;03(01):5-10. http://dx.doi.org/10.3126/jaim.v3i1.10695

9. Tuladhar AS, Shrestha A, Pradhan S, Manandhar DN, Chhetri PK, Rijal A ,Poudel P,Maskey A, Bhoomi KK. USG assisted and USG guided percutaneous renal biopsy at Nepal Medical College Teaching Hospital: A three and half years study. Nepal Med Coll J 2013; 15(3): 179-182

10. Roccatello D, Sciascia S, Rossi D, et al. Outpatient percutaneous native renal biopsy: safety profile in a large monocentric cohort. BMJ Open 2017;7:e015243. doi:10.1136/ bmjopen-2016-015243

11. Krishna A, Vardhan $H$, Singh $P$, Kumar O. Analysis of Native Kidney Biopsy: Data from a Single Center from Bihar, India Saudi J Kidney Dis Transpl 2018;29(5):1174-1180

12. Sharma A, Deo RK, Shahi R R. Pattern of glomerular disease in a tertiary care hospital in Nepal: A Shree Birendra Hospital experience. Journal of College of Medical Sciences-Nepal, $2011,7(4) 48-52$

13. Khakurel S, Agrawal RK, Hada R. Pattern of Glomerular Disease in Nepal: A Single-center Experience. Saudi J Kidney Dis Transpl 2015;26(4):833-838

14. Aryal G, Kafle RK. Hisopathological spectrum of glomerular disease in Nepal: a seven-year retrospective study. Nepal Med Coll J 2008; 10(2): 126-128

15. Woo KT, Glassock RJ and Lai KN. IgA Nephropathy: Discovery of a Distinct Glomerular Disorder. In: Woo KT (ed). Clinical Nephrology. 3rd edition. World Scientific. 2011 http://dx.doi. org/10.1142/8094

16. Galla JH. IgA nephropathy. Kidney Int 1995; 47:377-87. http:// dx.doi.org/10.1038/ki.1995.50

17. Kim JK, Kim JH, Lee SC, Kang EW, Chang TI. Clinical Features and Outcomes of IgA Nephropathy with Nephrotic Syndrome. Clin J Am Soc Nephrol. 2012 Mar 07; 7(3): 427-36.

18. O'Shaughnessy M, Hogan S, Bawana D, Cop $\neg$ po R, Fogo A, Jennette C: Glomerular disease frequencies by race, sex and region: results from the International Kidney Biopsy Survey. Nephrol Dial Transpl 2017, DOI: 10.1093/ndt/gfx189.

19. Szeto CC, Lai FM, To KF, Wong TY, Chow KM, Choi PC, Lui SF, Li PK. The natural history of immunoglobulin A nephropathy among patients with hematuria and minimal proteinuria. Am J Med 2001;110:434-437. [PubMed: 11331053]

20. Yu L, Guo R, Li H, Xie X, Jiang N, Zhao W, Feng X. The pathologic and epidemic characteristics of 618 cases of IgA nephropathy in Shaanxi area. Journal of Xi' An Jiatong University (Medical Sciences) 2005;26:450-453.

21. Abdou N, Boucar D, El Hadj Fary KA, Mouhamadou M, Abdoulaye L, Mamadou Mourtala KA, et al. Histopathological profiles of nephropathies in senegal. Saudi J Kidney Dis Transpl. 2003 Apr-Jun;14(2):212-4.

22. Korbet SM, Genchi RM, Borok RZ, et al. The racial prevalence of glomerular lesions in nephrotic adults. Am J Kidney Dis. 1996 May; 27(5):647-51. http://dx.doi.org/10.1016/S02726386(96)90098-0

23. Braden GL, Mulhern JG, O'Shea MH, et al. Changing incidence of glomerular diseases in adults. Am J Kidney Dis. 2000 May; 35(5):878-83. http://dx.doi.org/10.1016/S0272$\underline{6386(00) 70258-7}$

24. Markowitz GS, Lin J, Valeri AM, Avila C, Nasr SH, D'Agati VD. Idiopathic nodular glomerulosclerosis is a distinct clinicopathologic entity linked to hypertension and smoking. Hum Pathol. 2002 Aug;33(8):826-35.

25. TK Chen, MM Estrella, and DM Fine. Predictors of kidney biopsy complication among patients with systemic lupus erythematosus. Lupus. 2012 July; 21(8): 848-854. doi:10.1177/0961203312439334 